\title{
Abrasive wear behavior of thermally sprayed diamond reinforced composite coating deposited with both oxy-acetylene and HVOF techniques
}

\author{
K. Venkateswarlu a,*, V. Rajinikanth ${ }^{a}$, T. Naveen ${ }^{\mathrm{a}, 1}$, Dhiraj Prasad Sinha ${ }^{\mathrm{b}}$, \\ Atiquzzaman $^{\mathrm{b}}$, Ajoy Kumar Ray ${ }^{\mathrm{a}}$ \\ a National Metallurgical Laboratory (NML), Jamshedpur 831007, India \\ ${ }^{\mathrm{b}}$ National Institute of Technology(NIT), Jamshedpur 831014, India
}

\section{A R T I C L E I N F O}

\section{Article history:}

Received 4 March 2008

Received in revised form 18 December 2008

Accepted 10 February 2009

Available online 21 February 2009

\section{Keywords:}

Diamond reinforced composite (DRC)

Abrasive wear

Thermal spray

HVOF

\begin{abstract}
A B S T R A C T
Diamond and diamond-based coatings have long been studied for their exceptional properties. Although a great deal of research has been carried out in this field, little is known about their tribological wear behavior. In the present work, diamond reinforced composite (DRC) coatings of varying diamond content was deposited on mild steel substrates using both oxy-acetylene (OA) and high velocity oxy fuel (HVOF) thermal spraying techniques. The high stress abrasive wear behavior of these coatings is studied by performing two body abrasion tests for varying experimental parameters. It is observed that the HVOF-sprayed coatings suffered abrasion at a relatively low wear rate. The reasons for variations observed in the wear rate as a function of displacement during abrasion and grit size could be attributed to the deterioration of abrasive particles and the particle size effect respectively. While the disparity in the wear rates with respect to composition of the coatings was primarily controlled by the diamond content in the coating. The abrasive wear mechanism was found to be the same in both the coatings except that the coating deposited by HVOF spray technique, offered better abrasion resistance and therefore abraded at a slower rate. This is possibly due to lower porosity in the coating and higher bond strength between reinforced diamond particulates and the bronze matrix in HVOF-sprayed specimens.
\end{abstract}

(C) 2009 Elsevier B.V. All rights reserved.

\section{Introduction}

Over the past few decades, there has been a considerable advancement in the theoretical know-how of abrasion and related wear phenomena. In regard to abrasive wear, it is studied that the hardness of the surface subjected to abrasion is of prime importance. The choice of surface material is almost completely based on its ability to inhibit large plastic deformation, formation of wear grooves and micro cracks etc. In the past, good results have been achieved by application of thick hard coatings. Super hard coatings have been employed in order to realize the enhancements in wear resistance associated with decrease in porosity of coating, increase in hardness and use of nanostructured feedstock material [1]. The development of wear resistant coatings has led to the evolution of several novel coating technologies. These are capable of depositing advanced thin coatings of WC, TiN, TiAlN, TiC, $\mathrm{Al}_{2} \mathrm{O}_{3}$ and $\mathrm{CrN}$ which are generally recommended for providing protection against abrasion [2]. The performance of these thin films was less remarkable under abrasive conditions than sliding. This is partially due to

\footnotetext{
* Corresponding author. Tel.: +91 657 2345253; fax: +91 6572345213.

E-mail address: karodi2002@yahoo.co.in (K. Venkateswarlu).

${ }^{1}$ Present address: University of Southern California, Los Angeles, USA.
}

thickness limitations of hard physical vapor deposition (PVD) and chemical vapor deposition (CVD) coatings, their lack of toughness and the need for effective load support especially under abrasion with sharp and hard abrasive particles. Besides, diamond-based and diamond-like carbon (DLC) coatings are also used to provide resistance against wear. It has been observed that DLC films possess exceptional qualities which make it ideal for a wide range of tribological applications. However, these films are not suitable for severe abrasion conditions [2]. Apart from these, diamond is also used in the powder form as reinforcement particulates in a composite mixture which is thermal sprayed on softer surfaces. The present work concerning the wear behavior of DRC coatings is different from the diamond film or diamond-like carbon films which are generally produced by vacuum deposition techniques. The optimal substrate temperature for pure diamond coating is about $900^{\circ} \mathrm{C}$, which severely limits the range of substrates for practical uses. Furthermore, it is difficult to sinter diamond powder to prepare monolithic diamond. Therefore, to exploit the hardness of diamond for various industrial applications, diamonds must be bonded with other materials. In view of this, diamond-based composites (bonded with metal and polymer) are developed and widely used in industries. In many of those engineering applications, the diamondbased composites are used in the form of coatings [3-6]. Though a large number of techniques are available for the fabrication of 
composite coatings, thermal and plasma spray coatings are industrially popular. Thermal spray technique being a low cost process can easily be adopted in industries [5]. The diamond-based composite coating on any substrate is expected to exhibit the following advantages: excellent wear and corrosion resistance (depending on the matrix). Several properties of the composites such as electrical resistivity, abradability or abrasive characteristics, surface texturing, catalytic and prosthetic applicability can be tailored. The DRC coatings are used in diamond polishing wheels, diamond wafer blades, metal scooping tools, etc. [3-5]. The application of this coating material is mainly dependent on the requirements. The diamond-based coating in general is subjected to abrasion and sliding wear during various operations [6]. Though a significant amount of work has been carried out on the sliding wear behavior of diamond-based composites [7-9], their abrasion behavior is not studied adequately. In this paper, the abrasion wear behavior of DRC coating fabricated by both OA and HVOF thermal spray technique is discussed based on their high stress abrasive wear behavior.

\section{Experimental}

\subsection{Feed stock material}

The feedstock material used for the coating consisted of tungsten carbide (WC) (average particle size: $\sim 2 \mu \mathrm{m}$ ), bronze (average particle size: $\sim 30 \mu \mathrm{m}$ ) and diamond (average particle size: $\sim 25 \mu \mathrm{m}$ ) powder. The powders were obtained from Metal Powder Company, Mumbai, India and were reported to be of $99.9 \%$ purity. Composite mixtures of three different compositions were selected, i.e. (Batch A: C-10\%, WC-25\% and bronze 65\%; Batch B: C-15\%, WC-25\% and bronze 60\%; and Batch C: C-20\%, WC-25\% and bronze-55\%). The composition of bronze was $85 \mathrm{wt} . \% \mathrm{Cu}$, and $15 \mathrm{wt} . \% \mathrm{Sn}$ in all the three mixtures. Each powder was thoroughly mixed for $10 \mathrm{~min}$ in a planetary ball mill (Freitz, PM 400, Germany) for uniform mixing of the constituents. Before proceeding for the spraying process, $1 \%$ urea solution along with requisite amount of water was added for effective globulisation of the feedstock powder. Besides ensuring an appreciable homogeneity within the globules, it also improves the flowability of the composite powder mixture. The powder was finally classified within -100 to +300 BSS mesh size and dried at $120^{\circ} \mathrm{C}$ for $1 \mathrm{~h}$ to remove volatile matter and moisture.

\subsection{Oxy-acetylene thermal spraying}

Before proceeding for thermal spraying of composite powder, the substrates were degreased for removal of all surface contaminants from the interstices and surface pores. In addition, the substrates were also polished using 120 grit emery paper in order to roughen the surface. This ensured better adherence of the coating particles on to the substrates. The mild steel substrate was then heated to a temperature $\sim 250^{\circ} \mathrm{C}$ using acetylene torch. This was done in order to minimize the thermal gradient between the film and the substrate during deposition which had a positive influence on the adherence of coating particles. While depositing the composite powder, the distance between the nozzle of the spraying gun and the substrate was kept $\sim 10 \mathrm{~cm}$ while the angle of deposition was maintained at $\sim 90^{\circ}$ in order to expel any volatile matter which otherwise could have affected the adherence of coating film. Finally, the coated specimens were polished using emery papers of appropriate grit size. This was done in order to impart smoothness to the coating surface and to remove loosely adhered particles. A uniform coating thickness of $\sim 500( \pm 50) \mu \mathrm{m}$ was maintained for all the specimens during deposition. The thickness was measured using coating thickness measurement tester (Quanix 8500, Germany).

\subsection{HVOF thermal spraying}

The deposition using HVOF spraying technique involved similar preparations for the substrate material as discussed above. The mild steel substrates were thoroughly degreased to make the interstices and surface pores devoid of the contaminants which otherwise could have led to surface oxidation. In order to achieve good bond strength which is particularly unique with the coatings deposited using HVOF technique, the substrates were also cleaned ultrasonically besides polishing them with 120 grit emery paper. Prior to deposition, the specimens were properly set up in the HVOF spraying unit. The process involved the mounting of mild steel specimens on the circumference of horizontally rotating turntable, maintained at an effective horizontal transverse rate during deposition. The gun system (HIPOJET4500, MEC, India) delivering a vertical transverse, was fixed on the transverse unit by a suitable mechanism. A mixture of oxygen, fuel gas (liquid petroleum gas) and a carrier gas (argon) along with the DRC powder was introduced into the combustion chamber. The pressures of oxygen, fuel and air was consistently maintained at 100,60 and $70 \mathrm{~kg} \mathrm{~cm}^{-2}$. When the gas mixture was ignited, the controlled hot gas jet accelerated the powder downstream along the nozzle to impact the substrate. The velocity of particles feeding was $\sim 180 \mathrm{~m} / \mathrm{s}$ measured by a laser jet particle velocity analyzer. Multiple detonations occurring within a short time at such higher velocities helped in obtaining a coating of sufficient thickness. Under the present working conditions, the temperature attained within the detonation gun was $\sim 1200^{\circ} \mathrm{C}$, measured by using an optical pyrometer. The substrates were maintained at a temperature of $\sim 200^{\circ} \mathrm{C}$ in order to avoid thermal expansion during the process of coating. The coating thickness measured after polishing of the HVOF-sprayed DRC coated samples was $\sim 500 \mu \mathrm{m}$, which is similar to that of OA-sprayed specimens.

\subsection{Abrasion wear tests}

Specimen dimensions of $40 \mathrm{~mm} \times 30 \mathrm{~mm} \times 5 \mathrm{~mm}$ were selected for abrasion wear test. The coating was done on one side of the specimens only. Before wear testing, the coated surfaces were polished with a 400-grit $\mathrm{SiC}$ emery paper to ensure proper contact between the coated surface and the abrasive media. The wear tests were conducted using an abrasion tester model TR 605 (Ducom, Bangalore, India). A schematic of the abrasion wear test machine is shown in Fig. 1. The SiC particles on the emery papers were in the size range of $30-110 \mu \mathrm{m}$ and the load applied was in the range

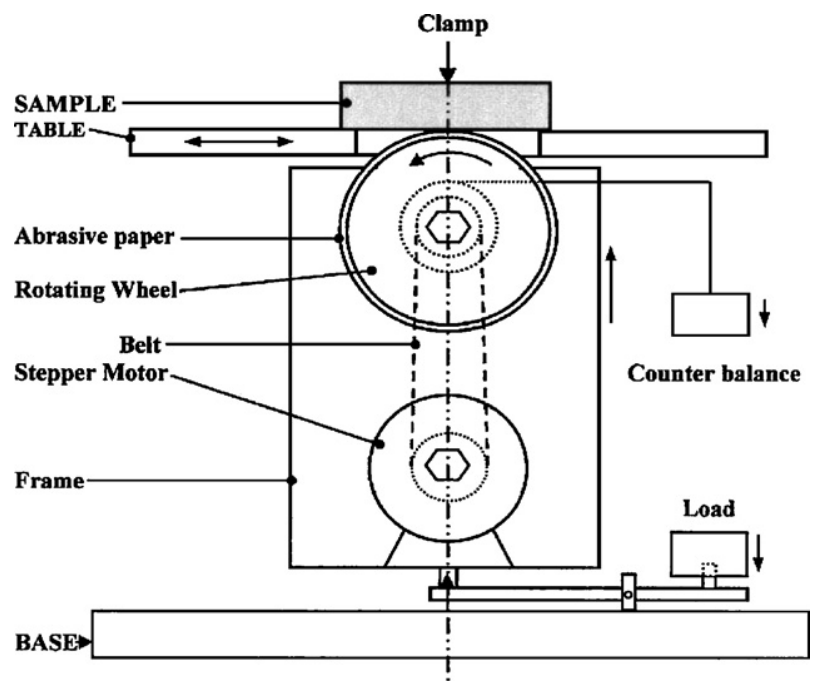

Fig. 1. Schematic diagram of two-body abrasion tester. 
of 7.5-15 N. The distance traversed in each case was limited to 400 cycles corresponding to $26 \mathrm{~m}$ (in each cycle the distance traversed on the sample was $65 \mathrm{~mm}$ ). The process in which the abrasion test was carried out included: (i) fixing the emery paper on the wheel firmly with the help of a double sided adhesive tape, (ii) samples of known weight were loaded on the machine and the load applied by means of a cantilever mechanism, (iii) the samples were subjected to reciprocating motion over the wheel on which the emery papers were embedded so that the specimen surface and the emery paper were always in strong contact with each other under the predetermined load, and (iv) the samples were cleaned thoroughly and weighed prior to and after each test interval. The wear rate was measured from the weight loss and expressed as the volume loss per unit distance traversed.

\section{Results and discussions}

\subsection{Characterization of DRC powder and coating}

Scanning electron microscope (SEM) images of the diamond and WC powders are shown in Fig. $2 a$ and $b$, respectively. The WC particles are in the size range of $1-3 \mu \mathrm{m}$ and are relatively finer than the diamond particles $(30 \pm 10 \mu \mathrm{m})$. The angularity observed in the shape of diamond is quite different from the globular shape of WC particles. The globular nature imparts agglomeration tendency to WC particles which is evident from the respective micrograph. Hence it is understood that for uniform distribution of different particles in the deposited coating, perfect milling of the composite
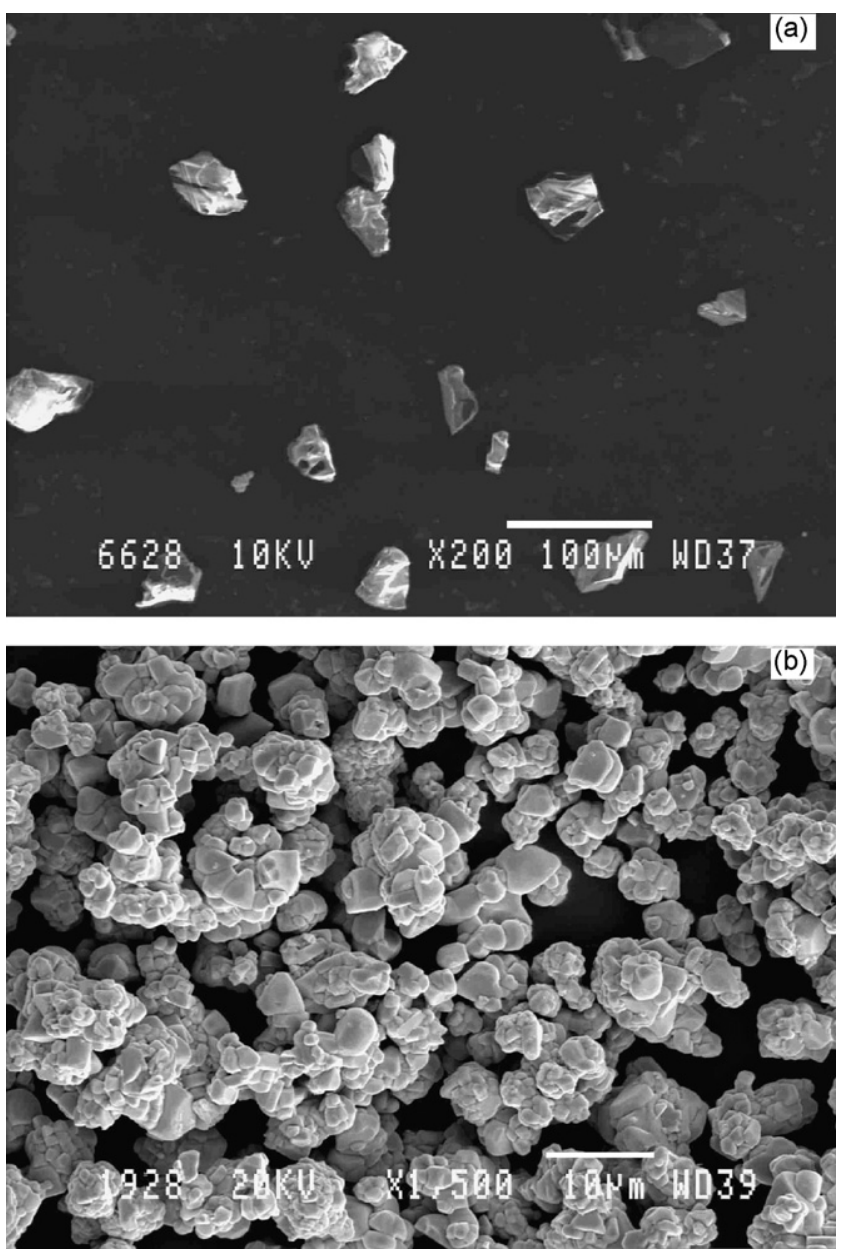

Fig. 2. SEM image of starting powders (a) diamond (b) WC. (a)

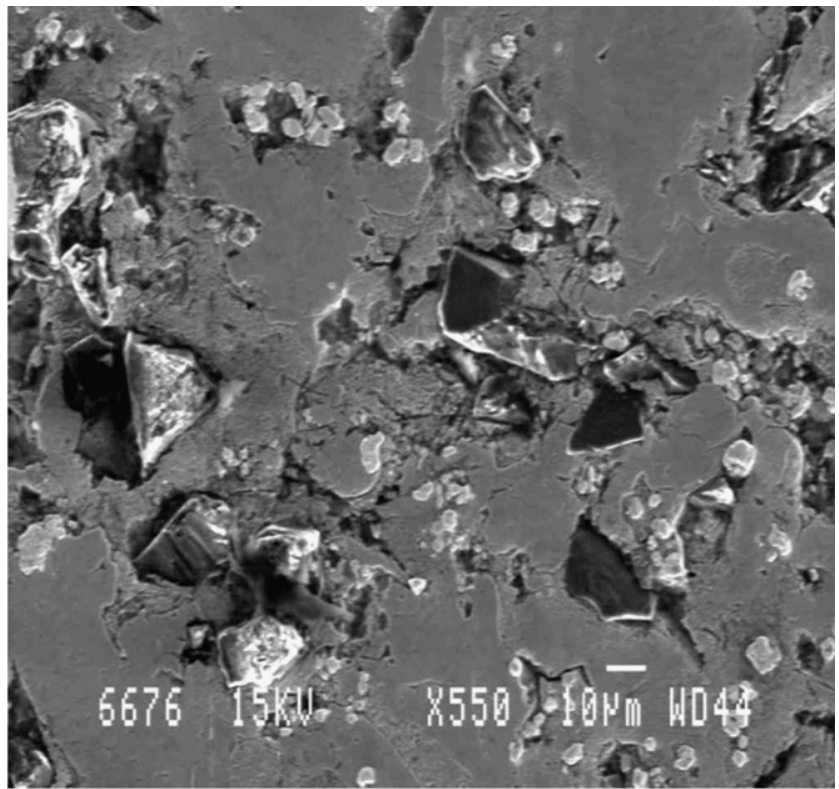

(b)

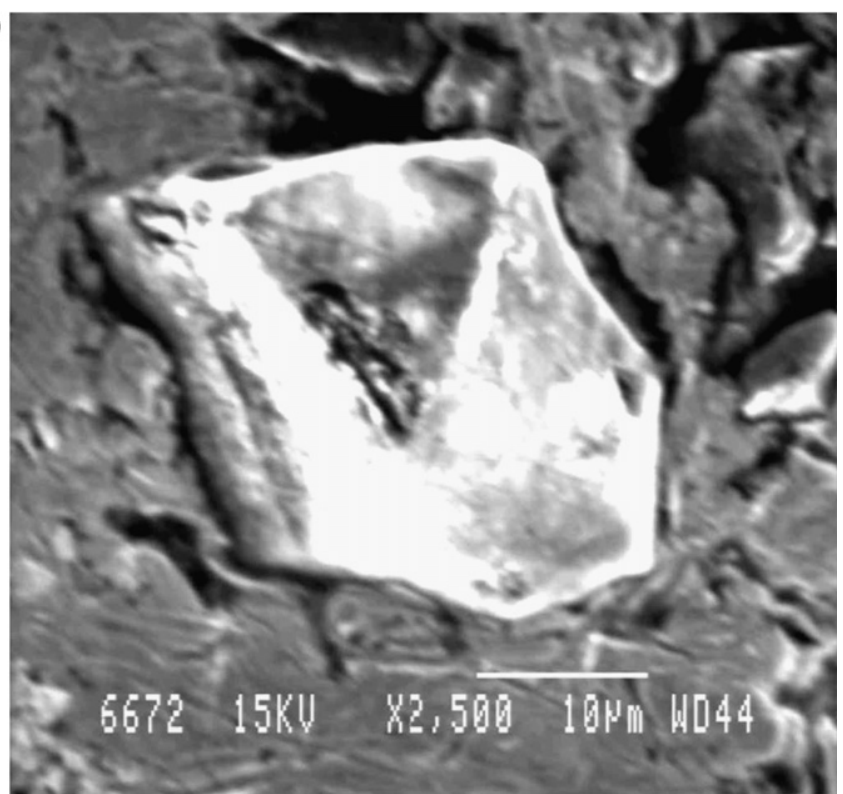

Fig. 3. SEM image of OA-sprayed DRC coatings of specimens (a) A and (b) C.

mixture for appropriate time in a planetary ball mill is quite essential. Fig. $3 a$ and $b$ shows the microstructures of specimen $A$ at lower magnification and specimen $C$ at higher magnification respectively with OA spray technique. It is noted that the diamond and WC particles are uniformly distributed within the bronze matrix. The appearance of grey shades represents the bronze rich binder matrix and the bright region is indicative of rich WC content. The particle size and morphology of diamond and WC particles did not change before and after the spraying process. Moreover, owing to the fineness of the WC particles, its agglomeration tendency appeared to have reduced in the coatings deposited with OA spray technique. The WC particles can be seen uniformly dispersed in the bronze matrix with minimum agglomeration in a few places. The reduced agglomeration is also due to the homogeneity within the DRC globules $[10,11]$. The interfacial bonding observed in case of OA-sprayed specimen is comparatively weaker and shown in Fig. 3b. The WC and diamond particles are loosely held in case of OA sprayed samples. In addition, there are porosities visible in the micrographs of 
(a)

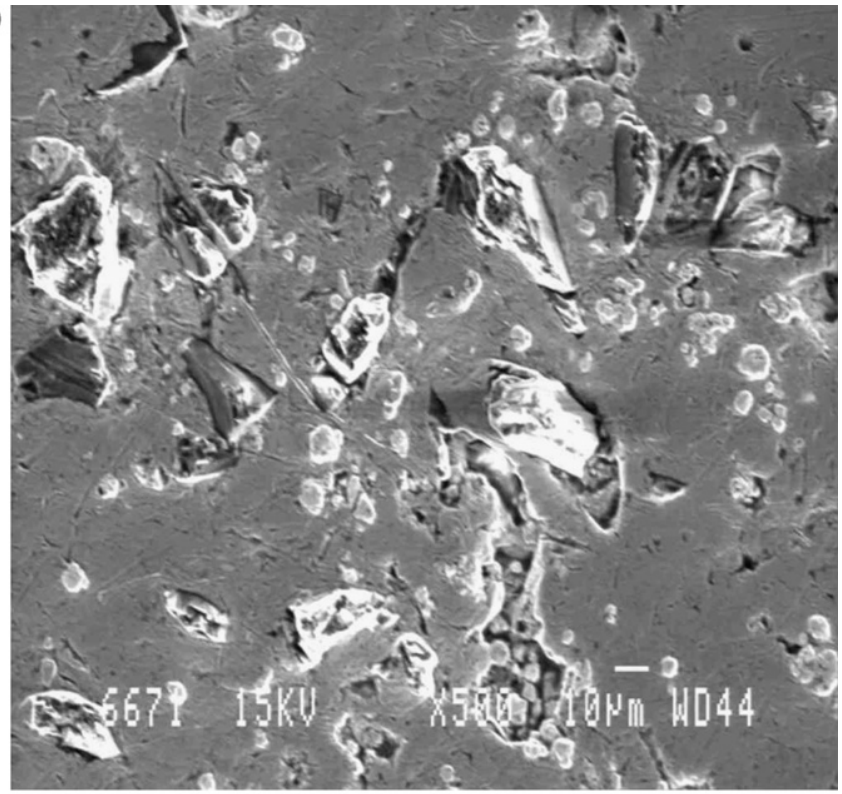

(b)

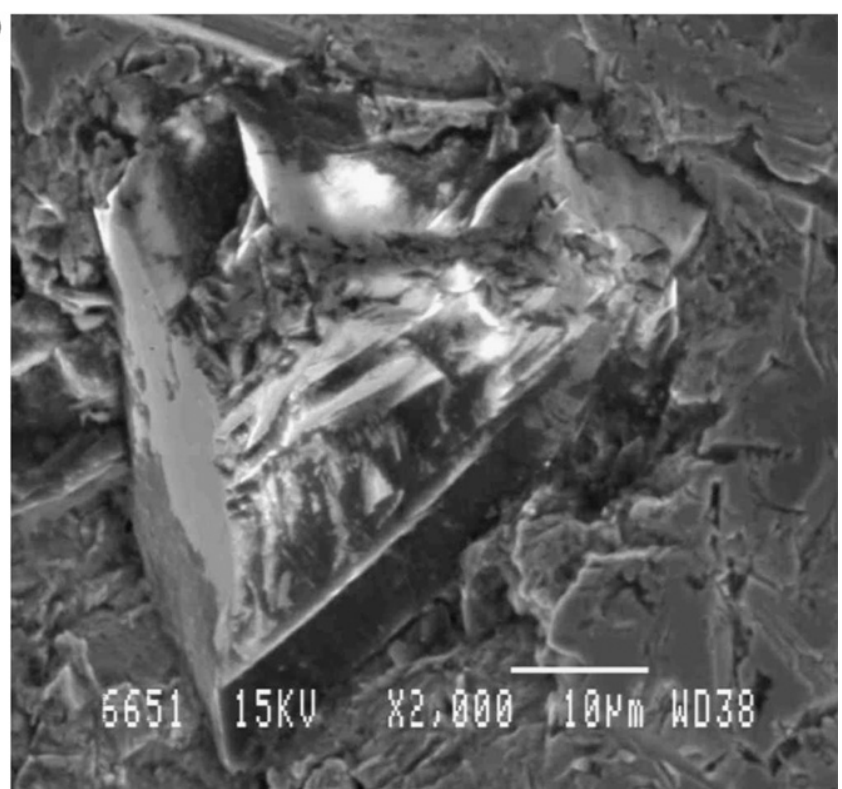

Fig. 4. SEM image of HVOF-sprayed DRC coatings of specimens (a) A and (b) C.

deposited coatings which are the main cause for relatively high wear rate observed in case of OA-sprayed coatings (Fig. 3a). The high bond strength between the reinforced particulates and the ductile bronze matrix of HVOF-sprayed specimen A is clearly seen in Fig. 4a. A good interfacial bonding between the bronze matrix and diamond particle in HVOF-sprayed specimen $C$ is evident from Fig. 4b. The diamond particles are strongly embedded in the bronze matrix. Moreover, the fine WC particles are also evenly dispersed in the bronze matrix, which imparts additional hardness and reinforcement to the matrix. This prevents severe deformation of the bronze matrix during abrasion against hard $\mathrm{SiC}$ particles. The deformation of the matrix around the diamond particles usually lead to the weakening of particle-matrix interface which results in pull out of diamond particles from the matrix. The porosity levels are lower in HVOF-sprayed samples. Fig. 4a also shows a few agglomerated WC particles close to the diamond particle. Besides, another discernible observation made in regard to the HVOF coating is the decomposition of WC particles. The application of high temperature during HVOF spraying led to the thermal decomposition of WC
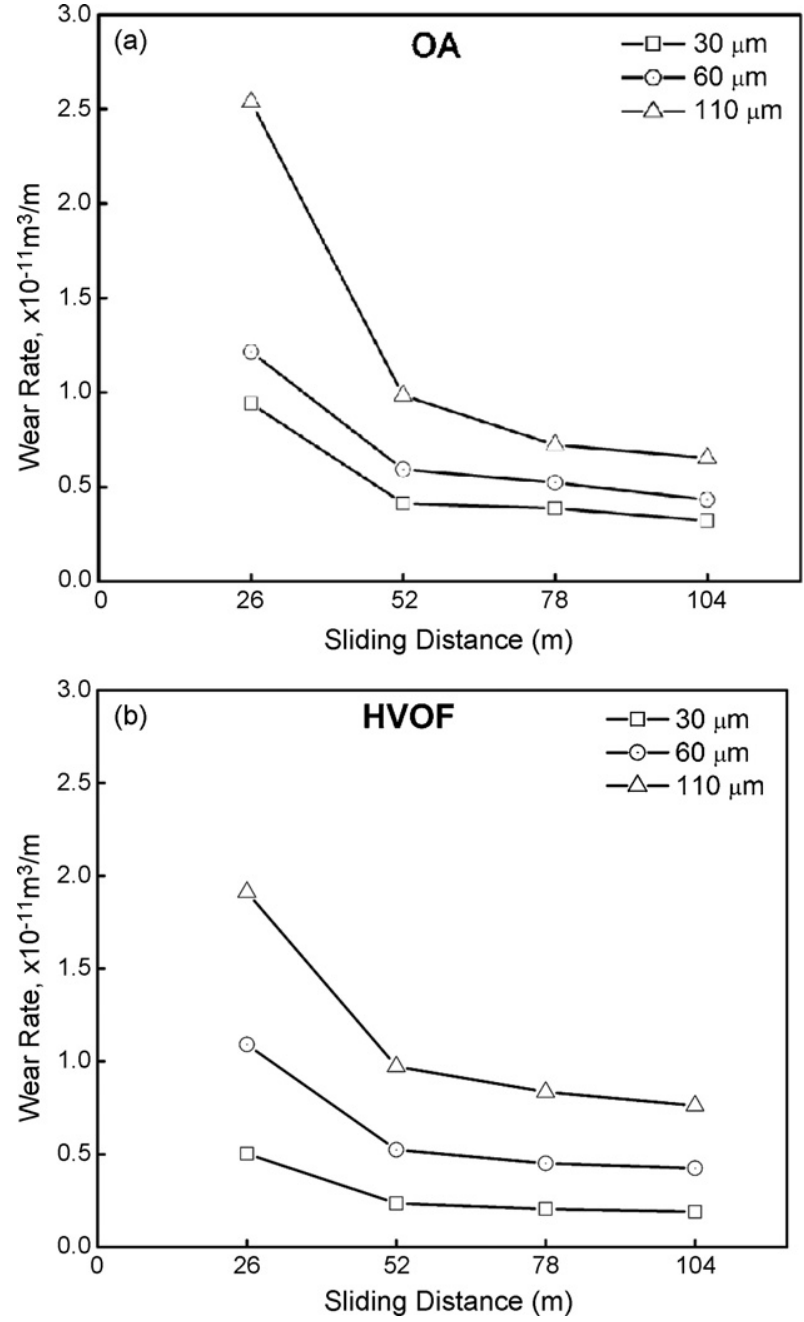

Fig. 5. Abrasive wear rate versus sliding distance of (a) OA and (b) HVOF-sprayed coatings.

to cause minor presence of $\mathrm{W}_{2} \mathrm{C}$ in the deposited coating. Though high particle velocity was maintained in order to offset for this high temperature, so as to allow less residence time to the WC particles still these underwent minor decomposition. Similar decomposition behavior of WC was studied by others [12,13]. The observations pertaining to porosity and bond strength is even supported by the hardness measurements. The average hardness of the mild steel substrate was measured $180 \mathrm{HV}$ while OA-sprayed specimens A, B, and $C$ measured 275, 295 and 308 HV respectively. However, the bulk hardness values of HVOF-sprayed specimens A, B and C are 300,320 and $335 \mathrm{HV}$ respectively, which are clearly higher than mild steel substrate and OA-sprayed coatings.

\subsection{Two body abrasion tests}

In the present work, the abrasive wear behavior of DRC coated specimens (both OA and HVOF-sprayed) was studied as a function of varying experimental parameters viz., composition of coating, abrasive particle size, sliding distance and applied load. It was observed that the wear mechanism in both the types of specimens is primarily controlled by the particle size effect. The wear behavior as observed from the graphical representations show the variations in wear rates of different specimens when subjected to changes in the aforementioned experimental parameters. Fig. 5 shows the decrease in wear rate of specimen A (OA and HVOFsprayed) as a function of sliding distances subjected to abrasion 
against emery paper embedded with $\mathrm{SiC}$ particles under different applied loads. Immediately after the first $26 \mathrm{~m}$ of abrasion, a sharp decline is observed in the wear rate beyond which there is a marginal reduction in wear rate up to $104 \mathrm{~m}$. Reasons for the drop in wear rate with increasing sliding distance could be attributed to the increase in roundness of the abrading particle asperities. It is considered that under real contact conditions during two body abrasive wear only a small number of sharp, conical asperity peaks support the applied load. If these asperities are used repetitively beyond a critical distance these begin to loose their sharpness and become blunted with increasing sliding distances. It is to be noted that in the first $26 \mathrm{~m}$ (comprising 400 cycles reciprocating motion) of displacement during abrasion, at every particular instants completely unabraded particles of $\mathrm{SiC}$ were exposed to the coating surface. Beyond $26 \mathrm{~m}$, those particles causing abrasion of the coating were already abraded once, twice or thrice in cases of 52, 78 and $104 \mathrm{~m}$ of distances traversed respectively. When the abrasive particles encountered the hard diamond particles, they underwent fragmentation and were displaced from their position, thus rendering ineffective abrasion. Consequently beyond $26 \mathrm{~m}$ of sliding displacement, the SiC particles on the emery paper were ineffective in causing appreciable abrasion of the DRC coating which is possibly due to the loss in sharpness of the asperities under abrasive contact. The decline in the wear rates with increasing sliding distances were observed in both OA and HVOF-sprayed specimens, irrespective of the applied load, grit size or the composition of coating. Earlier, deterioration of abrasive grits as the possible cause for
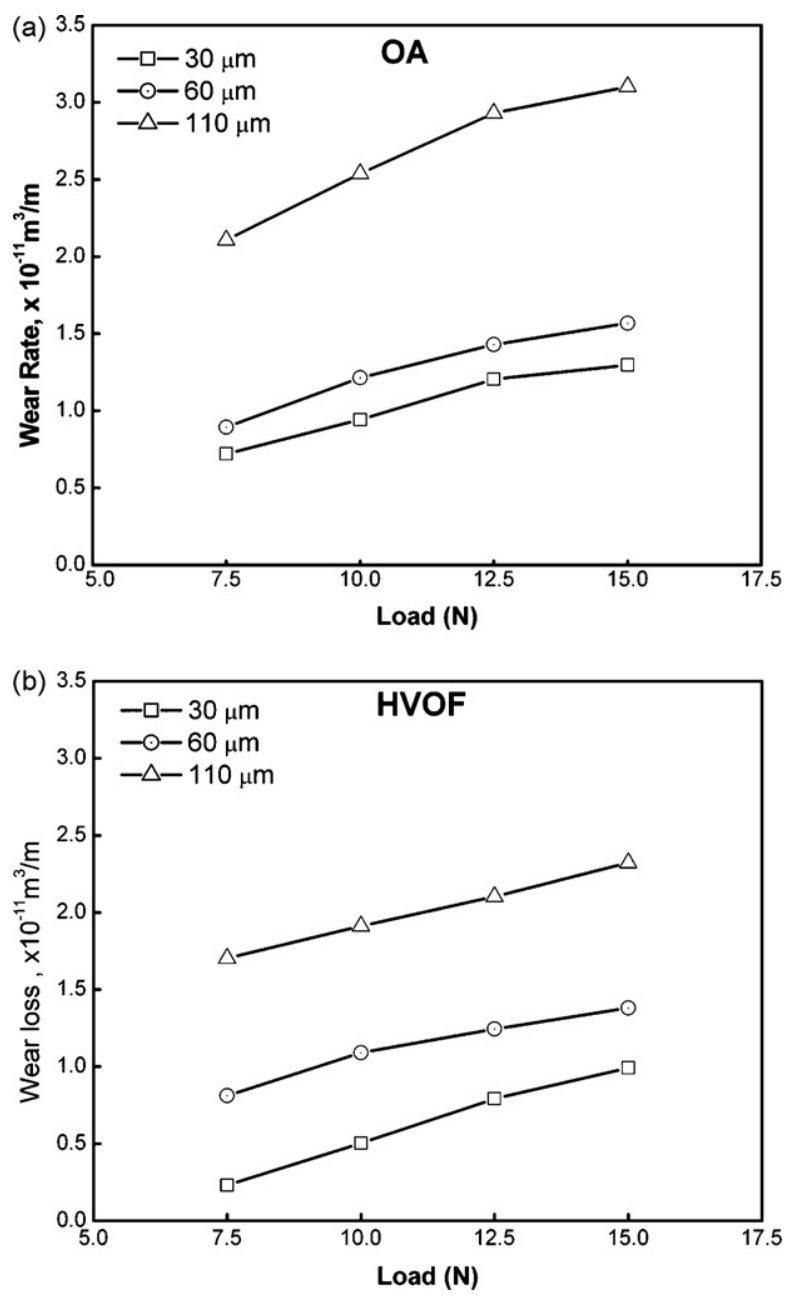

Fig. 6. Abrasive wear rate versus load of (a) OA and (b) HVOF-sprayed specimen A. declining wear rates has been proposed [14]. While others suggest a material strengthening mechanism, often called the strained gradient effect, at reduced scales [15]. Abrasion induces deformation in the subsurface region which in turn causes work hardening of the matrix material. In addition, if the deformed layer is stable and intact, it prevents further wear. This results in reduced wear rate. But the stability of the work hardened matrix may be lost due to increased micro cracking tendency of the matrix. This is possible in cases of composite coatings possessing hard reinforced particulates which lead to reduced influence of work hardening on the abrasive wear rate [16]. Moreover, recent computer simulations involving the modeling of asperities as spherically tipped cones, have confirmed the influence of particle size on particle shape effect which in turn controls the abrasive wear rate [17,18]. Hence this study was intentionally confined to the variations in abrasive wear behavior of specimens observed within $26 \mathrm{~m}$ of distance traversed, while completing 400 cycles of reciprocating motion. Fig. $6 a$ and $b$ shows the variations in wear rates of specimen $A$ as a function of different grit sizes for OA and HVOF spray techniques respectively. It was observed that the wear rate increased with increasing grit size or vice versa but, this variation was not proportional. The reduction in wear rates with decrease in particle size could be explained on the basis of particle size effect. It is generally considered that the particle size effect is manifested at particle sizes below $100 \mu \mathrm{m}$ [19-22]. Hence to study the dominance of particle size effect the size of abrading media ( $\mathrm{SiC}$ particles) was selected within the range of $30-110 \mu \mathrm{m}$. The increase in wear rate was marginal when the
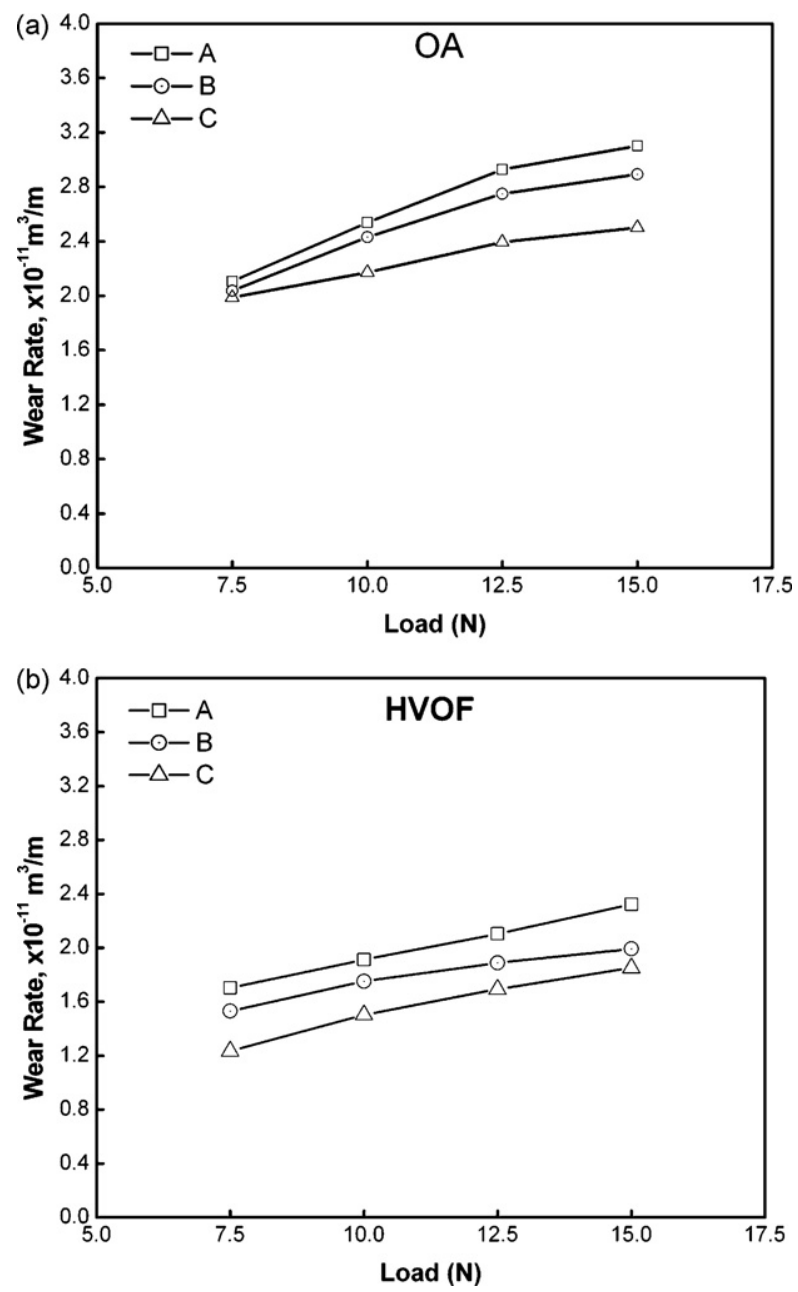

Fig. 7. Abrasive wear rate versus load of (a) OA and (b) HVOF-sprayed specimens A, $\mathrm{B}$, and $\mathrm{C}$. 
grit size increased from 30 to $60 \mu \mathrm{m}$. However war rate for $110 \mu \mathrm{m}$ showed a significant increase in the wear rate. This is significant of the fact that in finer size range, the size of abrasive particles has a prominent role on wear rate. This is in good agreement with the argument which proposes that smaller particles experience abrasive contact for relatively greater displacement and are therefore more prone to deterioration. Hence the particles in the smaller size range are ineffective in exercising significant influence on abrasive wear rate. This trend is found prevalent in the wear behavior of both OA and HVOF-sprayed specimens. Besides, there was a significant increase in wear rate when the grit size increased to $110 \mu \mathrm{m}$. The increase in applied load caused a significant increase in the wear rate irrespective of the abrasive size. Higher applied loads led to an increase in the depth of penetration and the depth of wear grooves. Higher applied loads and coarser abrasive size together caused the formation of micro cracks which in turn led to greater material volume loss and hence facilitated the increase in wear rate. For low loads, the large valleys in between the contacting asperities acted as reservoirs of debris accumulation. The wear debris clogging the valleys played a substantial role in separating the surfaces and mitigating the wear [23]. This was more likely when the particle size decreased [23]. With increased loads, it is understood that the asperity penetration is high and it is possible that the debris are more effectively cleared into the surface valleys [23]. Increasing the applied load produces more debris but at the same time compresses them as expected. The wear debris is then pushed out of the way during abrasive contact. The above facts also explain the cause of sudden change in wear rate when the grit size changed to $110 \mu \mathrm{m}$. The increasing wear resistance of the DRC coating caused by the increase in diamond concentration is quite clear from the Fig. 7a and $b$ that shows wear rate plotted against applied load for $O A$ and HVOF-sprayed specimens (A, B and C). It is also observed that larger diamond concentration of the coatings presents the lower wear rate. Even WC particles exercise significant influence on the wear behavior by improving the hardness of the base matrix. Both WC and diamond particles play a synergistic influence in improving the wear resistance of the coating but, the diamond concentration is an extremely important variable. It is significant of the degree of matrix wear out that can occur. If the concentration is too low, rapid matrix wear out occurs, resulting in greater wear loss. In contrast, if the diamond concentration is high, the matrix becomes inaccessible to wear out to any significant depth. Still very high concentration of diamond should be avoided, for then there is insufficient matrix to facilitate formation of a strong bond between the reinforcing particulates and the substrate. In addition, coatings possessing higher diamond content are quite expensive. The wear behavior is found to be dominated by the following salient factors. (i) The hardness of the surface coating exposed to abrasive wear conditions. (ii) Presence of protruding hard diamond and WC particles to provide protection to the bronze matrix from the abrasive wear action of abrading media (SiC particles embedded on the emery paper). (iii) The ability of hard particles to withstand the applied effective load so that it remained intact on the surface. In addition, these factors are believed to influence the width and depth of the wear grooves as well. If the depth/width of the grooves is greater than that of hard reinforced particles, the influence of the particle reinforcements on the improvement in wear resistance is significantly less. Often, the influence could be negligible. For instance the SiC particles of
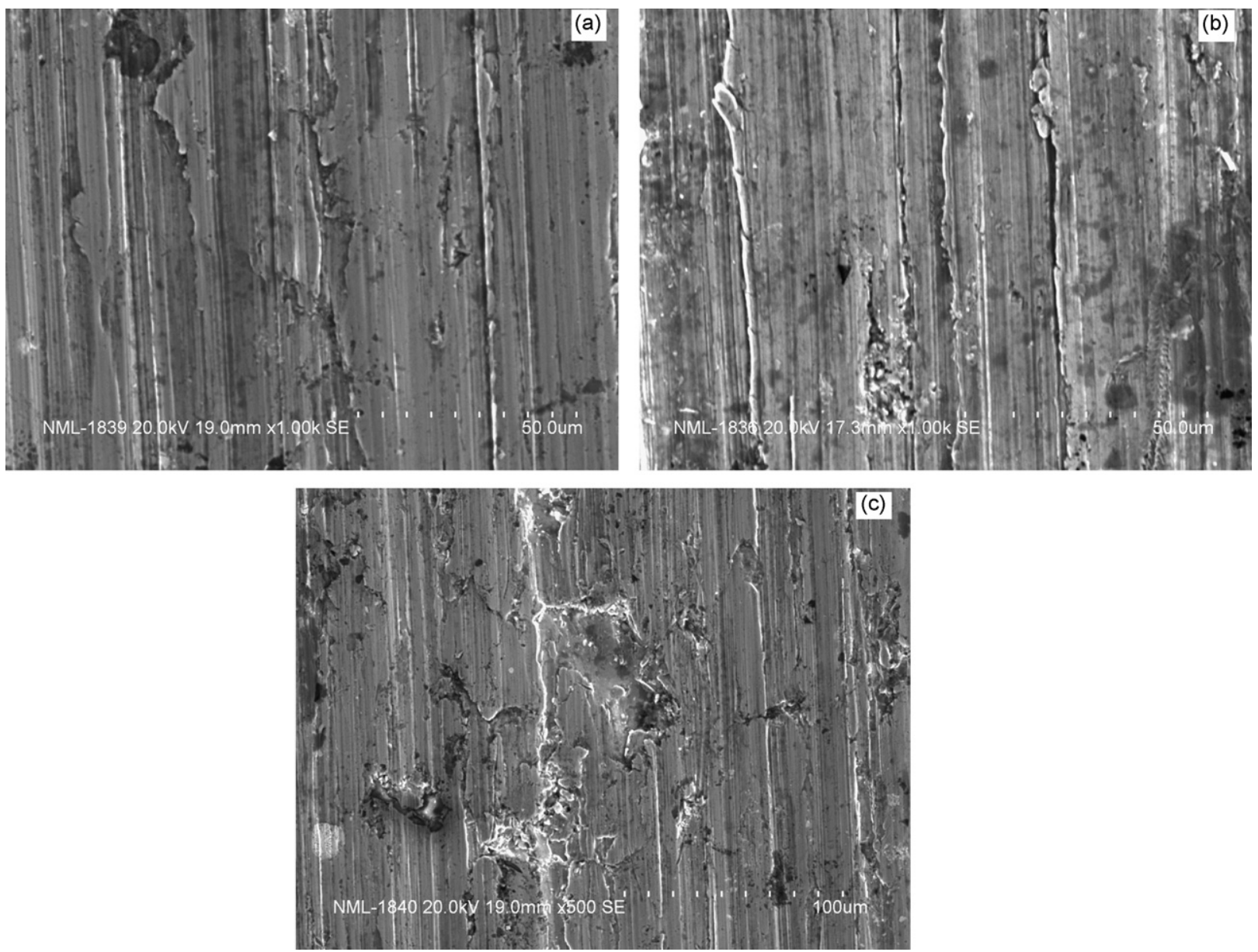

Fig. 8. Example of wear track of specimen A for (a) OA, (b) HVOF-sprayed coatings (c) OA-sprayed coating at lower magnification. 
size 30 and $60 \mu \mathrm{m}$ made wear grooves of depth much less than the size of diamond particles. But, still the depth of wear grooves was greater than that of the size of WC particles. However, the presence of fine WC particles is expected to improve the strength and hardness of the matrix materials and hence believed to facilitate the formation of fine wear grooves. Under such circumstances, the wear rate is primarily governed by the protruding hard diamond particles by controlling the depth of penetration by the abrading particles on the coating surface. In contrast, when the abrasive size was increased to $110 \mu \mathrm{m}$, the depth and width of the wear grooves formed were relatively greater in size when compared with that of diamond and WC particles. Finally, comparison was made between the abrasive wear resistant performance of OA and HVOF-sprayed specimens. This involved the present wear results for OA vis-à-vis HVOF-sprayed specimens. The difference in wear rates as a function of different experimental parameters can be seen clearly in Figs. 5 and 6. The wear performance delivered by the HVOF specimens is clearly better than that of OA specimens, irrespective of whether the plot is against grit size or composition of the coating. The plausible reasons for this could be the high bond strength between the diamond reinforcements and the bronze matrix. If the bond strength between the particles and matrix is poor, the gap acts as micro cracks. Hence higher wear loss is expected under such conditions. The angularity in the shape of diamond particles facilitated better holding of the particles in the matrix. The optimum sharpness of the cutting edges ensured minimum effective forces on the particles. In addition, even the agglomerations of WC particles present in the matrix provide good resistance against abrasion and hence inhibit the deformation of matrix. As concerns the mechanism governing the wear of DRC coatings, it is proposed that when the SiC particles came into contact with the coated surface under the application of fixed load, the stresses imposed by the hard, sharp asperities of $\mathrm{SiC}$ particles caused deformation and consequent extrusion of the bronze matrix. The matrix underwent severe deformation thereby causing a reduction in the matrix support, which was earlier imparted to the WC and diamond reinforcements. Subsequently prolonged abrasion of the coating led to the micro cracking and pullout of reinforced particulates, under the conditions of reduced matrix support. The severity of the deformation suffered by the matrix in OA-sprayed specimens is clear from Fig. 8, which shows the wear tracks formed during the abrasion of specimen A with OA and HVOF-spray techniques. The HVOFsprayed specimen suffered relatively less deformation and hence offered better resistance to abrasion. The wear debris formed was collected and the elemental composition was confirmed through Energy Dispersive Spectroscopy (EDS) analysis. Fig. 9 shows the SEM image of wear tracks formed on the wear debris during abrasion of OA-sprayed coating. Fig. 10a and b shows the peaks of different elements present in the EDS of wear debris of specimen A for OA and HVOF spray techniques respectively, abraded under an applied load of $10 \mathrm{~N}$. It is clear from the EDS analysis that there is a relatively higher percentage of $\mathrm{Cu}$ and $\mathrm{Sn}$ present in the wear debris of OA-sprayed coating which signifies greater matrix wear out. In addition, the presence of tungsten (W) gives a clear understanding of the severity of abrasion which led to the pull out of fine WC particles. It also speaks about the relatively weak bonding of reinforced particles. In contrast, the absence of $\mathrm{W}$ in the debris formed during the abrasion of HVOF-sprayed coating delineates better performance of the matrix which suffered relatively less deformation and hence resisted the fracture and subsequent pull out of WC particles. The plausible reasons for this behavior could be attributed to the size of diamond particles. The size of diamond particles is larger than that of WC particles. A small particle is easily dislodged by an encounter with abrasive grain, while a larger particle can withstand the same encounter and protect the underlying matrix. If the diamond particles are larger, matrix wear out ceases after a cer-

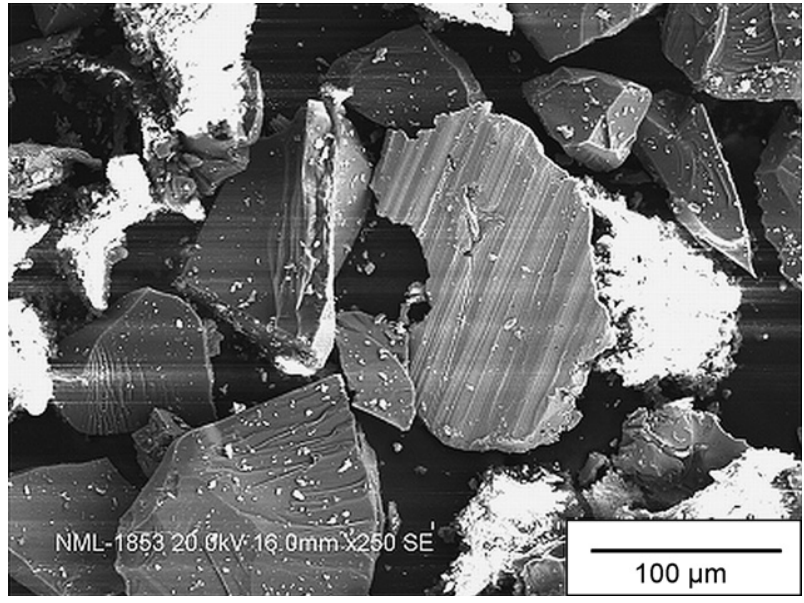

Fig. 9. Wear track on the debris of OA-sprayed specimen A.

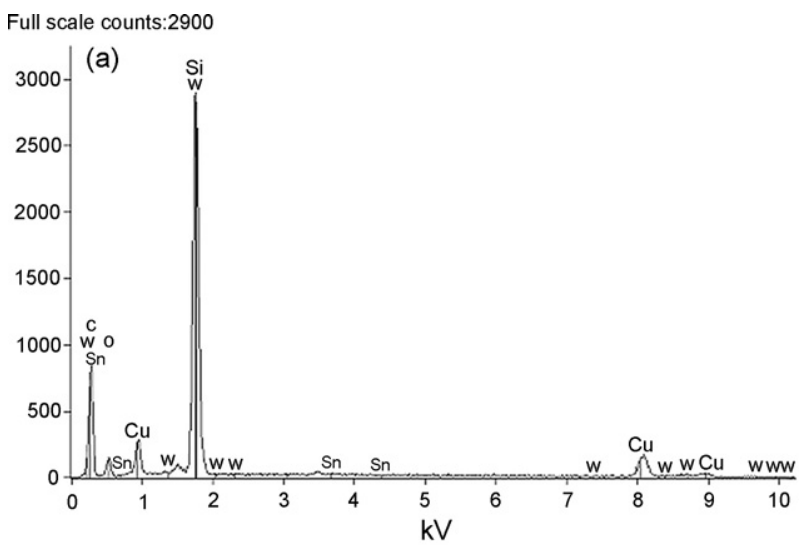

Full scale sounts: 2754

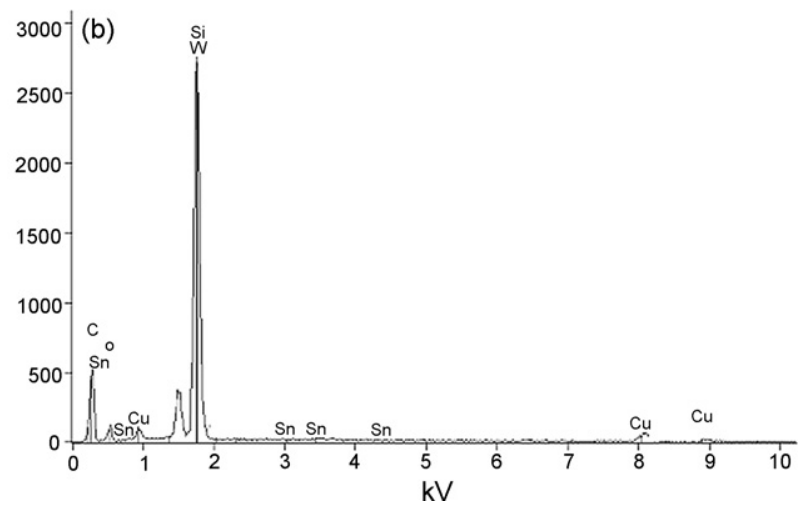

Fig. 10. EDS of wear debris of specimen A (a) OA and (b) HVOF-sprayed specimen.

tain depth is reached. Hence the diamond particles imparted much greater wear resistance than the WC particles and this is more pronounced in case of HVOF-sprayed coatings where the bond strength is relatively high.

\section{Conclusions}

DRC coatings of varying diamond concentration were deposited on mild steel substrates with OA and HVOF spraying techniques. The OA-sprayed specimens readily suffered abrasion in comparison to those deposited with HVOF spray technique under similar experimental conditions. It is concluded that the HVOF-sprayed 
specimens owing to its lower porosity and higher bond strength between reinforced particulates and the matrix led to substantial reduction in the deformation of matrix which in turn facilitated higher wear resistance. This is the prime reason for the disparity observed in the wear rates of the coatings deposited using two different techniques. In addition to the high hardness of HVOF-sprayed coating, the uniform distribution of diamond particles in the matrix is considered important in the view of reduced matrix deformation. The reduction in the wear rates with increasing displacement during abrasion is due to the deterioration of abrasives which caused loss of abrasiveness. While the variations in the wear rates as a function of abrasive size is mainly controlled by the particle size effect. The increase in abrasive grit size from finer to coarser was responsible for the increase in wear rate, but the effect was marginal for finer grit sizes.

\section{Acknowledgement}

The authors would like to thank Prof. S.P. Mehrotra, Director, NML, Jamshedpur, for his kind permission to publish this paper. We would also like to thank Mr. Manoj Kumar Gunjan for his SEM work. In addition, the authors are grateful to Dr. B.K. Prasad and Dr. L.C. Pathak for their critical suggestions. Our sincere thank to Mr. S.C. Modi, MECPL, Jodhpur for his valuable suggestions. The work has partially financed by Department of Science and Technology, Government of India, New Delhi.

\section{References}

[1] H. Chen, C. Xu, Q. Zhou, I.M. Hutchings, P.H. Shipway, J. Liu, Micro-scale abrasive wear behaviour of HVOF sprayed and laser-remelted conventional and nanostructured WC-Co coatings, Wear 258 (2005) 333-338.

[2] Tribology in Practice Series, Wear-Material, Mechanism and Practice, in: G.W. Stachowiak (Ed.), John Wiley \& Sons Inc., 2005.

[3] P.M. Natishan, R.K. Everett, J.W. Glesener, P.E. Pehrsson, B. Maruyama, A.S. Edelstein, A.A. Morrish, Mater. Sci. Eng. A 197 (1995) 79-81.

[4] P.K. Bachman, R. Messier, Emerging technology of diamond thin films, Chem. Eng. News (1989) 24-39.

[5] K.E. Spear, Diamond-ceramic coating of the future, J. Am. Ceram. Soc. 72 (1989) 171-191.
[6] T. Neykova, J. Kourtev, I. Petrov, V. Orlinov, Investigation of ion-assisted deposition diamond-like carbon films, Bulg. J. Phys. 17 (1990) 52-59.

[7] I.Sh. Trakhtenberg, S.A. Plotnikov, O.M. Bakunin, S.G. Yakovleva, A.A. Nechaev S.D. Gorpinchenko, A.B. Vladimirov, L.G. Korshunov, N.V. Gavrilov, V.N. Mizgulin, The effect of additional treatment on tribological properties of amorphous carbon coatings on metals, Diam. Relat. Mater. 7 (1995) 1020-1024.

[8] S.D. Gorpinchenko, I.Sh. Trakhtenberg, O.M. Bakunin, S.A. Plotnikov, A.A. Nechaev, V.N. Mizgulin, N.V. Gavrilov, Breakdown of A-C coatings on ionimplantation-modified metal alloys with a jet of abrasive particles, Diam. Relat. Mater. 3 (1994) 779-782

[9] I.Sh. Trakhtenberg, S.A. Plotnikov, A.B. Vladimirov, Ya.L. Liberman, V.A. Kanalina, V.A. Boborykin, V.M. Leizerov, Service properties of cutting tools hardened with a diamond like coating, Diam. Relat. Mater. 2 (1993) 1434-1438.

[10] K. Venkateswarlu, A.K. Ray, M.K. Gunjan, D.P. Mondal, L.C. Pathak, Tribological wearbehavior of diamond reinforced composite coating, Mater. Sci. Eng. A 418 (2006) 357-363.

[11] K. Venkateswarlu, S. Mohapatra, R.G. Rao, A.K. Ray, L.C. Pathak, D.P. Mondal, High abrasive wear response of diamond reinforced composite coating: a factorial design approach, Tribol. Lett. 24 (2006) 7-14.

[12] Q. Yang, T. Senda, A. Hirose, Sliding wear behavior of WC $-12 \%$ Co coatings at elevated temperatures, Surf. Coat. Technol. 200 (2006) 4208-4212.

[13] T. Sudaprasert, P.H. Shipway, D.G. McCartney, Sliding wear behaviour of HVOF sprayed WC-Co coatings deposited with both gas-fuelled and liquid-fuelled systems, Wear 255 (2003) 943-949.

[14] J. Larsen-Badse, Some effects of specimen size on abrasive wear, Wear 19 (1972) 27-35.

[15] H.Mcl. Clark, R.B. Hartwich, A re-examination of the 'particle size effect' in slurry erosion, Wear 248 (2001) 147-161.

[16] B.K. Prasad, K. Venkateswarlu, S. Das, A.K. Jha, R. Dasgupta, Influence of SiC reinforcement on the abrasive wear response of an Al-Cu alloy under conditions of varying abrasive size and applied load, J. Mat. Sci. Lett. 16 (1997) 1113-1115.

[17] J. Jiang, F. Sheng, F. Ren, Modeling of two-body abrasive wear under multiple contact conditions, Wear 217 (1998) 35-45

[18] R. Gahlin, S. Jacobson, The particle size effect in abrasion studied by controlled abrasive surfaces, Wear 224 (1999) 118-125.

[19] D.V.De Pellegrin, G.W.Stachowiak, Assessing the role of particle shape and scale in abrasion using 'sharpness analysis': Part I. Technique development, Wear 253 (2002) 1016-1025

[20] D.V. De Pellegrin, G.W. Stachowiak, in: D. Dowson, et al. (Eds.), Tribology Series 39, Elsevier, 2001, pp. 517-1517.

[21] J. Goddard, H. Wilman, A theory of friction and wear during the abrasion of metals, Wear 5 (1962) 114-135.

[22] H. Sin, N. Saka, N.P. Suh, Abrasive wear mechanisms and the grit size effect, Wear 55 (1979) 163-190.

[23] D.V. De Pellegrin, G.W. Stachowiak, Evaluating the role of particle distribution and shape in two-body abrasion by statistical simulation, Tribol. Int. 37 (2004) 255-270. 